\title{
Is there any relationship between plasma antioxidant capacity and lung function in smokers and in patients with chronic obstructive pulmonary disease?
}

\author{
Irfan Rahman, Elzbieta Swarska, Michael Henry, Jan Stolk, William MacNee
}

\begin{abstract}
Background-It has been suggested that oxidative stress is an important factor in the pathogenesis of chronic obstructive pulmonary disease (COPD). We have shown that an oxidant/antioxidant imbalance occurs in the distal air spaces of smokers and in patients with COPD which is reflected systemically in the plasma. A study was undertaken to determine whether plasma antioxidant status correlated with lung function as assessed by forced expiratory volume in one second $\left(F E V_{1}\right)$ and forced vital capacity (FVC) in smokers and patients with COPD.
\end{abstract}

Methods-Plasma antioxidant capacity, assessed by the Trolox equivalent antioxidant capacity (TEAC) as an index of overall systemic oxidative stress, and protein thiol levels were measured in 95 patients with stable COPD, in 82 healthy smokers, and in 37 healthy non-smokers.

Results-Mean (SE) plasma TEAC levels were significantly decreased in patients with COPD (0.81 (0.03) $\mathrm{mmol} / \mathrm{l}, \mathrm{p}<0.001)$ and in healthy smokers $(0.87(0.04) \mathrm{mmol} /$ $1, p<0.001)$ compared with healthy nonsmokers (1.31 (0.11) mmol/1). The mean differences in plasma antioxidant capacity ( $\mathrm{mM})$ were $(0.81,95 \%$ confidence interval (CI) 0.22 to 1.48$),(0.87,95 \%$ CI 0.2 to $1.46)$, and (1.31, 95\% CI 1.09 to 1.58$)$ in patients with COPD, healthy smokers, and healthy non-smokers, respectively. This reduction was associated with a $29 \%$ (95\% CI 18 to 38 ) and a $30 \%$ (95\% CI 19 to 40) decrease in plasma protein thiol levels in COPD patients and smokers, respectively. Current smoking was not the main contributor to the reduction in antioxidant capacity in patients with COPD as those patients who were still smokers had similar TEAC levels (mean (SE) 0.78 $(0.05) ; \mathbf{n}=25)$ to those who had stopped smoking $(0.84(0.02) ; n=70)$. No significant correlations were found between spirometric data measured as $\mathrm{FEV}_{1} \%$ predicted or $\mathrm{FEV}_{1} / \mathrm{FVC} \%$ predicted and the plasma levels of TEAC in patients with COPD, healthy smokers, or healthy nonsmokers. Similarly, there was no significant correlation between FEV 1 predicted or $\mathrm{FEV}_{1} / \mathrm{FVC} \%$ predicted and the levels of plasma protein thiols in the three groups.
Conclusions-These data confirm decreased antioxidant capacity in smokers and patients with COPD, indicating the presence of systemic oxidative stress. However, no relationship was found between protein thiols or TEAC levels and measurements of airflow limitation in either smokers or in patients with COPD. (Thorax 2000;55:189-193)

Keywords: oxidants; antioxidants; protein thiols; smoking; chronic obstructive pulmonary disease

Reactive oxygen species (ROS) generated from leucocytes in the blood or air spaces or inhaled in the form of environmental oxidant pollutants are scavenged by antioxidants and antioxidant enzymes. These antioxidant systems include enzymes such as superoxide dismutases, catalase, glutathione peroxidase; proteins such as albumin, ceruloplasmin, bilirubin and ferritin; and small molecules including ascorbic acid, reduced glutathione, $\alpha$-tocopherol, $\beta$-carotene, ubiquinol-10, methionine, and uric acid. The ability of an individual to counteract the damaging effects of free radical assault depends on the antioxidant capacity in an organ or body fluid.

An oxidant/antioxidant imbalance in favour of oxidants in the airways has been proposed as a factor in the pathogenesis of chronic obstructive pulmonary disease (COPD). ${ }^{1}$ More than $90 \%$ of patients with COPD are smokers, but not all smokers develop COPD. ${ }^{2}$ The increased oxidant burden in smokers derives from the fact that cigarette smoke contains more than 1014 free radicals/oxidants per puff and is a complex mixture of over 4700 chemical compounds. ${ }^{3}$ Short lived oxidants such as superoxide anion $\left(\mathrm{O}_{2}{ }^{-}\right)$and nitric oxide (NO) are predominantly found in the gas phase. $\mathrm{O}_{2}{ }^{-}$ and NO react chemically to form highly cytotoxic oxidant peroxynitrite $\left(\mathrm{ONOO}^{-}\right)$. Free radicals in the tar phase of cigarette smoke are organic in nature, such as long lived semiquinone radicals which can react with $\mathrm{O}_{2}{ }^{-}$to form hydroxyl radical $(\bullet \mathrm{OH})$ and $\mathrm{H}_{2} \mathrm{O}_{2}{ }^{4}$ Increased oxidative stress in patients with COPD also comes from the increased sequestration of neutrophils in the microvasculature which have the potential to release enhanced amounts of ROS. $^{56}$

Understanding the mechanisms of smoking induced lung injury and the factors which determine a rapid decline in lung function may 
potentially lead to prediction of which smokers will progress to develop significant disease. In the light of this, we have recently shown that the antioxidant capacity is decreased in the plasma of smokers and of patients with exacerbations of COPD. ${ }^{78}$ In addition, there are numerous reports showing decreased levels of plasma antioxidants and increased markers of oxidative stress in the lungs, bronchoalveolar lavage fluid, and plasma of smokers and patients with COPD compared with normal subjects (reviewed by Rahman and $\mathrm{MacNee}^{1}$ ). There is also evidence of increased levels of markers of oxidative stress such as hydrogen peroxide $^{910}$ and 8 -isoprostane- $\mathrm{F}_{2 \alpha}$ (an oxidative by product of arachidonic acid $)^{11}$ in the exhaled breath of smokers and in patients with COPD. These data suggest that smoking can cause oxidative modification of biomolecules in biological fluids in vivo and thereby impose cell/tissue injury and inflammation, which are the hallmarks of inflammatory lung diseases such as COPD. Epidemiological studies have shown that some of these markers of oxidative stress may be associated with reduced lung function. An example of this is the inverse relationship between circulating neutrophil numbers and the $\mathrm{FEV}_{1} \cdot{ }^{12} \mathrm{In}$ addition, a high dietary intake of the antioxidant vitamins $\mathrm{C}$ and $\mathrm{E}$ has been shown to relate to better lung function in the general population ${ }^{13}$ and to a lower prevalence of chronic bronchitis in smokers, ${ }^{14}$ suggesting a protective effect of these vitamins. Shunemann et al have recently reported a negative correlation between plasma lipid peroxides, which are a measure of oxidative stress, and lung function in non-smokers. ${ }^{15}$ However, there are conflicting reports available on the association between an oxidant/antioxidant imbalance and lung function in healthy subjects and in smokers. ${ }^{16}$

The purpose of this study was to confirm the hypothesis that an oxidant/antioxidant imbalance occurs in smokers and in patients with COPD and to correlate this with the degree of airflow obstruction. We therefore measured plasma antioxidant capacity and the levels of protein sulphydryls and correlated these with lung function in healthy non-smokers, healthy smokers, and in patients with COPD. We also examined the effects of smoking and sex differences on the antioxidant capacity in these subjects.

\section{Methods}

PATIENTS

Ninety five patients with clinically stable COPD were studied, 35 of whom were recruited from the outpatient clinics at the Royal Infirmary, Edinburgh, 32 from the Department of Respiratory Medicine, University College, Dublin, and 28 from the Department of Pulmonology, Leiden University Medical Center, Leiden, The Netherlands. The characteristics of these patients are given in table 1 . The diagnosis of COPD was made by a respiratory physician on the basis of current or ex-smoking and largely irreversible airways obstruction with $<15 \%$ improvement in baseline forced expiratory volume in one second in response to inhaled $\beta_{2}$ agonist. The clinical condition of the patients was stable, with no acute exacerbations of COPD in the month prior to entry into the study. Twenty five patients were current smokers and 70 were ex-smokers who had stopped smoking between six weeks and five years before their participation in the study.

At the time of the study 72 of the 95 patients had been receiving inhaled corticosteroid treatment for more than two years. All the patients were receiving inhaled bronchodilator therapy in the form of short acting $\beta_{2}$ agonists and/or anticholinergic agents.

Forced expiratory volume in one second $\left(\mathrm{FEV}_{1}\right)$ and forced vital capacity (FVC) were measured with a bellows spirometer (Vitalograph Ltd, Buckingham, UK). FEV 1 and FVC were expressed as a percentage of the predicted values for age, sex, and height based on the ERS guidelines, and $\mathrm{FEV}_{1}$ of $>70 \%$ predicted was considered to be normal. The spirometric data from these patients are given in table 1 .

CONTROL SUBJECTS

Healthy smokers/non-smokers

Eighty two healthy smokers recruited from hospital staff and the general population (32 from Edinburgh, 30 from Dublin and 20 from Leiden) participated in the study. Their characteristics and spirometric data are shown in table 1. Thirty one subjects were current smokers and 51 were ex-smokers who had stopped smoking six weeks to four years before their participation in the study. None was receiving any medications and specifically no inhaled bronchodilators or corticosteroids.

Thirty seven healthy non-smokers who had no history of lung disease and normal lung function were recruited from the hospital staff and used as control subjects.

The study was approved by the local ethical committee and all patients/subjects gave written informed consent.

\section{ASSAYS}

For all of the assays described below, $10 \mathrm{ml}$ of venous blood were withdrawn into a lithium heparin tube, centrifuged at $250 \mathrm{~g}$, the plasma removed and used for the following assays.

Plasma antioxidant capacity

Plasma antioxidant capacity was measured by the method of Rice-Evans and Miller. ${ }^{17}$ The Trolox equivalent antioxidant capacity

Table 1 Mean (SD) characteristics of healthy non-smokers and smokers with and without COPD

\begin{tabular}{|c|c|c|c|}
\hline Characteristics & Non-smokers & Smokers & $C O P D$ \\
\hline $\mathrm{M}: \mathrm{F}$ & $21: 16$ & $53: 29$ & $55: 40$ \\
\hline Age (years) & $58(8)$ & $59(7)$ & $66(9)$ \\
\hline \multicolumn{4}{|l|}{ Smoking status } \\
\hline Current smokers & - & 31 & 25 \\
\hline Ex-smokers & - & 51 & 70 \\
\hline Pack years & & $22(6)$ & $18(4)$ \\
\hline $\mathrm{FEV}_{1}(\%$ predicted $)$ & $102(18)$ & $89(16)$ & $45(11)$ \\
\hline FVC (\% predicted) & $104(15)$ & $93(17)$ & $64(14)$ \\
\hline \multicolumn{4}{|l|}{$\mathrm{FEV}_{1} / \mathrm{FVC}$ ratio } \\
\hline (\% predicted) & $103(16)$ & $88(18)$ & $54(10)$ \\
\hline
\end{tabular}

$\mathrm{FEV}_{1}=$ forced expiratory volume in one second $\mathrm{FVC}=$ forced vital capacity. 
(TEAC) was calculated by defining the concentration $(\mathrm{mmol} / \mathrm{l})$ of the vitamin $\mathrm{E}$ analogue Trolox that had the equivalent antioxidant capacity to $1.0 \mathrm{mmol} / 1$ of the plasma sample under investigation.

Protein sulphydryl

Protein thiols were measured using the method of Ellman. ${ }^{18}$

STATISTICAL ANALYSIS

The data are expressed as mean (SE). Differences between values were assessed by ANOVA. Correlations between the various parameters were calculated using Spearman's correlation coefficient.

\section{Results}

The plasma antioxidant capacity was significantly decreased in healthy smokers (mean difference $0.87,95 \%$ confidence interval (CI) 0.2 to $1.46 ; \mathrm{p}<0.001)$ and in patients with COPD (mean difference $0.81,95 \%$ CI 0.22 to 1.48 ; $\mathrm{p}<0.001$ ) compared with non-smoking healthy subjects (mean difference $1.31,95 \%$ CI 1.09 to 1.58 ; table 2). There was no significant difference in the plasma antioxidant capacity between current or ex-smokers in either the healthy subjects or those with COPD (table 2). In addition, there were no significant sex differences in the plasma antioxidant capacity in smokers or in patients with COPD (table 3). Serum albumin and haemoglobin levels in patients with COPD were 41.2 (1.7) $\mathrm{g} / 1$ and 128.1 (13.2) g/l, respectively, and in healthy smokers they were $39.8(1.4) \mathrm{g} / \mathrm{l}$ and 131.1 (15.1) $\mathrm{g} / \mathrm{l}$, respectively, and were all within the normal range.

The decreased levels of antioxidant capacity in smokers and in patients with COPD was associated with decreased levels of protein thiols in plasma compared with non-smoking healthy subjects $(\mathrm{p}<0.01$; table 2$)$. This reduction in protein thiols was estimated at $29 \%$

Table 2 Mean (SE) plasma antioxidant capacity (TEAC) and protein thiols in healthy non-smokers, smokers, and patients with COPD

\begin{tabular}{lll}
\hline Subjects & Antioxidant capacity & Protein thiols $(m M)$ \\
\hline Healthy non-smokers $(\mathrm{n}=31)$ & $1.31(0.11)$ & $0.56(0.06)$ \\
Healthy smokers $(\mathrm{n}=82)$ & $0.87(0.04)^{\star \star}$ & $0.39(0.03)^{\star}$ \\
Current smokers $(\mathrm{n}=31)$ & $0.90(0.05)^{\star \star}$ & $0.42(0.03)^{\star}$ \\
Ex-smokers $(\mathrm{n}=51)$ & $0.83(0.04)^{\star \star, \mathrm{NS}}$ & $0.38(0.03)^{\star, \mathrm{NS}}$ \\
COPD $(\mathrm{n}=95)$ & $0.81(0.03)^{\star \star}$ & $0.40(0.03)^{\star}$ \\
Current smokers $(\mathrm{n}=25)$ & $0.78(0.05)^{\star \star}$ & $0.43(0.04)^{\star}$ \\
Ex-smokers $(\mathrm{n}=70)$ & $0.84(0.02)^{\star \star, \mathrm{NS}}$ & $0.38(0.02)^{\star, \mathrm{NS}}$ \\
\hline
\end{tabular}

${ }^{\star} \mathrm{p}<0.01,{ }^{\star \star} \mathrm{p}<0.001$ compared with healthy non-smokers and non-significant (NS) compared with current smokers.

Table 3 Mean (SE) plasma antioxidant capacity and protein thiols in non-smokers, smokers, and patients with COPD according to sex

\begin{tabular}{lll}
\hline Subjects & Antioxidant capacity $(\mathrm{mM})$ & Protein thiols $(\mathrm{mM})$ \\
\hline Healthy non-smokers & $1.35(0.13)$ & \\
$\quad$ Men ( $\mathrm{n}=21)$ & $1.31(0.09)$ & $0.57(0.05)$ \\
$\quad$ Women (n = 16) & $0.89(0.04)^{\star \star}$ & $0.55(0.06)$ \\
Healthy smokers & $0.85(0.05)^{\star \star, \mathrm{NS}}$ & $0.41(0.03)^{\star}$ \\
$\quad$ Men (n = 53) & $0.83(0.02)^{\star \star}$ & $0.37(0.03)^{\star, \mathrm{NS}}$ \\
$\quad$ Women (n = 29) & $0.80(0.04)^{\star \star, \mathrm{NS}}$ & $0.40(0.02)^{\star}$ \\
COPD & & $0.40(0.03)^{\star, \mathrm{NS}}$ \\
Men (n = 55) &
\end{tabular}

${ }^{\star} \mathrm{p}<0.01,{ }^{\star \star} \mathrm{p}<0.001$ compared with healthy non-smokers and non-significant (NS) compared with men.

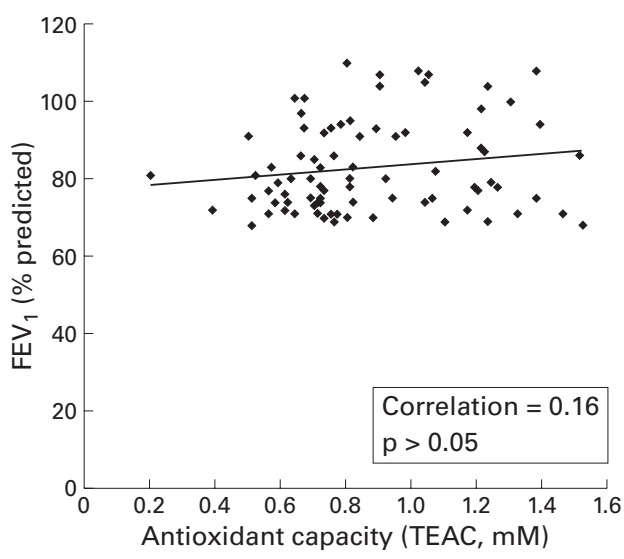

Figure 1 Relationship between lung function measured as forced expiratory volume in one second ( FEV $)$ and plasma antioxidant capacity (TEAC) in smokers.

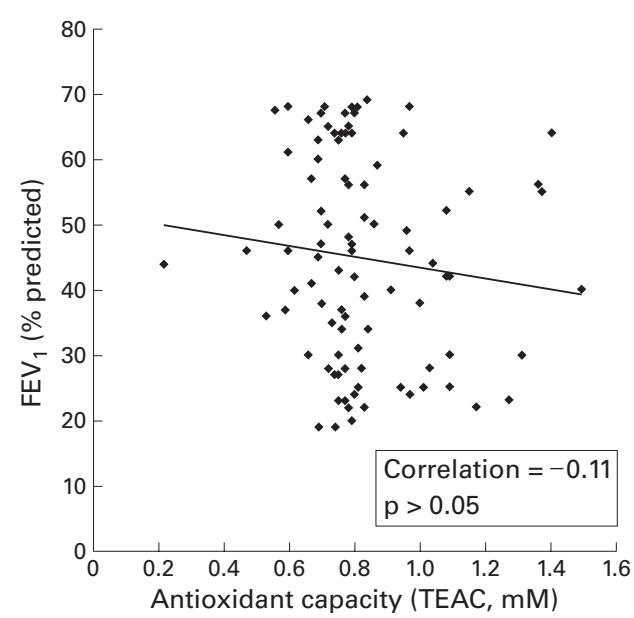

Figure 2 Relationship between forced expiratory volume in one second (FEV) and plasma antioxidant capacity in patients with COPD.

(95\% CI 18 to 38 ) in patients with COPD and $30 \%$ (95\% CI 19 to 40$)$ in healthy smokers. No difference in protein thiol levels was found between current and ex-smokers or between male and female subjects (tables 2 and 3 ).

The 72 patients with COPD who were receiving inhaled corticosteroids at the time of the study had mean (SE) plasma TEAC levels of $0.89(0.35) \mathrm{mM}$ and plasma protein thiol levels of $0.38(0.05) \mathrm{mM}$, which were similar to those of the 23 patients who did not receive corticosteroids (TEAC 0.84 (0.27), p>0.05; protein thiols $0.41(0.05), \mathrm{p}>0.05)$.

Spirometric values, particularly $\%$ predicted $\mathrm{FEV}_{1}$, in non-smokers, smokers, and in patients with COPD did not show any significant correlation with either the level of the antioxidant capacity or with protein thiols (figs 1 and 2). Similarly, there was no correlation between the $\mathrm{FEV}_{1} / \mathrm{FVC}$ ratio (\% predicted) and the antioxidant capacity or protein thiol levels in healthy non-smokers, smokers, or in patients with COPD (data not shown).

\section{Discussion}

Several methods have been developed to assess the total antioxidant capacity of human serum or plasma. This is because of the difficulty in measuring each antioxidant component sepa- 
rately and the interactions between different antioxidant components in the serum or plasma. ${ }^{19}$ Using a method devised by Miller et al we have previously reported that the Trolox equivalent antioxidant capacity (TEAC) of the plasma was lower in smokers and in patients with exacerbations of COPD than in age matched healthy subjects. ${ }^{78}$ In this paper we have extended our study to a larger population of patients from three European centres (Edinburgh, Dublin, and Leiden) and confirmed our earlier observations of low antioxidant capacity in the plasma of smokers and patients with COPD. We provide further insights into the relationship between lung function and the antioxidant status in smokers and in patients with stable COPD.

A decreased plasma antioxidant capacity was observed in all the patients with COPD and in healthy smokers. We also showed that the decreased plasma antioxidant capacity was concomitant with a decrease in the levels of plasma protein sulphydryls in smokers and in patients with COPD, suggesting a mechanism for the fall in TEAC levels. ${ }^{20}$ Several components of plasma contribute to plasma TEAC. Albumin, which has a sacrificial sulphydryl group, is thought to account for two thirds of the plasma TEAC. ${ }^{17}{ }^{19}$ Although the levels of protein thiols were lower in smokers and patients with COPD, the plasma albumin levels remained stable. Many proteins such as ceruloplasmin, transferrin, and small antioxidant molecules such as non-protein thiols, vitamins $\mathrm{C}$ and $\mathrm{E}$, and uric acid account for the remainder of the plasma TEAC. ${ }^{17}$ It has been reported that smoking is associated with a depletion of vitamins $\mathrm{C}$ and $\mathrm{E}$ in the blood. ${ }^{21} 22$ The lower plasma TEAC in patients with COPD and in chronic smokers could therefore result from depletion of such antioxidant molecules in addition to depletion of protein thiols.

A low antioxidant capacity in plasma suggests an increased oxidant burden in the blood. We and others have reported increased levels of superoxide anion release from circulating neutrophils ${ }^{723}$ and increased lipid peroxidation products in the plasma ${ }^{72}$ of smokers and patients with COPD, supporting the concept of systemic oxidative stress in these conditions. It is unclear, however, whether the oxidative stress that occurs in smokers is a direct effect of the oxidants/free radicals present in cigarette smoke or whether the endogenous inflammatory response is primarily responsible.

Smoking is known to produce systemic oxidative stress. ${ }^{20}$ We have previously shown that acute smokers have low plasma antioxidant defences compared with chronic smokers. ${ }^{74}$ In this study in a larger population we did not find significant differences in plasma TEAC and protein thiol levels between current smokers and ex-smokers, either in a healthy smoking population or in patients with COPD. However, the effects of acute smoking in these subjects and patients were not studied. This suggests that current smoking was not the main contributor to the reduction in levels of TEAC and protein thiols in patients with COPD. A possible explanation for the differ- ence in this and our previous study ${ }^{7}$ may lie in the greater control over the immediate smoking history in our earlier study. Indeed, our observation in COPD is supported by the recent findings of Nowak et al who found no direct effects of cigarette smoking on the levels of lipid peroxidation products and $\mathrm{H}_{2} \mathrm{O}_{2}$ in the expired breath condensate of smokers and patients with COPD, ${ }^{25}$ suggesting that disease state rather than current smoking accounts for the systemic oxidative stress in patients with COPD.

We also did not find any sex differences in the levels of TEAC and protein sulphydryls in healthy non-smokers, smokers, or in patients with COPD, nor was there any relationship with age in these subjects. A similar lack of sex dependent change in the glutathione concentrations has been reported in lymphocytes. ${ }^{26}$ However, a further study did show a decrease in glutathione concentrations and the activities of glutathione peroxidase and glutathione S-transferase with age. ${ }^{27}$ However, another study reported no age dependent change in the plasma levels of lipid peroxidation products in the general population. ${ }^{28}$

It has been suggested that long term corticosteroids have a beneficial effect on lung function in patients with chronic airflow obstruction. ${ }^{29}$ It is known from in vitro studies that corticosteroids inhibit the generation of ROS by neutrophils. ${ }^{30}$ However, we did not find evidence that treatment with steroids altered the plasma antioxidant capacity or protein thiol levels in patients with COPD. Similarly, in our previous studies we also did not find any significant differences in the levels of antioxidant capacity following treatment with corticosteroids in patients with acute exacerbations of COPD. ${ }^{7}$ Thus, our data showing the lack of differences in the plasma antioxidant capacity and protein thiols in these two groups could not be attributed to differences in treatment.

Recently there has been considerable interest in the association between dietary intake of antioxidants and measurements of systemic oxidative stress and lung function/symptoms in the general population and in smokers. ${ }^{13} 1516$ The hypothesis is that a diet rich in antioxidants may help to protect the body against airway inflammation and lung damage caused by cigarette smoke and inhaled environmental pollutants. Thus, individual susceptibility to chronic airways disease may be determined by the ability of the body to deal with inhaled oxidants. However, we found that neither the plasma antioxidant capacity nor protein thiol levels correlated significantly with spirometric data in healthy non-smokers, smokers, or patients with COPD. Schunemann et $a l^{15}$ also found no significant correlation between serum antioxidant capacity measured as TEAC and $\mathrm{FEV}_{1}$ in a general population, whereas they found an inverse correlation between the levels of lipid peroxidation and lung function. Our data do not support the observation that higher levels of dietary vitamin $\mathrm{C}$ or $\beta$-carotene protect against the development of airways obstruction in healthy non-smoking 
subjects $^{13}{ }^{16}$ and in patients with COPD. ${ }^{29}{ }^{31} \mathrm{~A}$ similar finding has also been reported from a study of a Scottish population, ${ }^{32}$ the Second United States National Health and Nutrition Examination Survey (NHANES II), ${ }^{33}$ and a study of middle aged men in the Netherlands, ${ }^{34}$ although other large epidemiological investigations have failed to find a protective effect of vitamins $\mathrm{C}$ and $\mathrm{E}$ and $\beta$-carotene on the decline in respiratory function measured as $\mathrm{FEV}_{1}$ or $\mathrm{FEV}_{1} / \mathrm{FVC}$ ratio. ${ }^{35}{ }^{36}$ Our negative findings may simply be due to the relatively small numbers studied compared with these population studies. Furthermore, the variability of oxidative stress occurring in smokers and patients with COPD may make it unlikely that measurement of the antioxidant capacity in the plasma would be likely to correlate with measurements of airway obstruction.

A further reason for failing to find a significant correlation between plasma antioxidant capacity and lung function may relate to differences in the intake of dietary antioxidants since antioxidant vitamin supplementation in smokers leads to the inhibition of lipid peroxidation and to recovery in lung function and an increase in plasma antioxidant capacity. ${ }^{37} 38$ Future work is needed to explore the possible relationship between the intake of individual antioxidants, systemic and local pulmonary assessment of antioxidant capacity/antioxidant molecules, and lung function.

In conclusion, this study confirms the presence of an oxidant/antioxidant imbalance systemically in smokers and in patients with COPD. The decrease in antioxidant capacity did not correlate with spirometric measurements of airway obstruction either in smokers or in patients with COPD.

This study was supported by the EUROLUNG-EU BIOMED 2 Grant No. BMH4-CT96-0152 and the British Lung Foundation.

1 Rahman I, MacNee W. Oxidant/antioxidant imbalance in smokers and chronic obstructive pulmonary disease. Thorax 1996;51:348-50.

2 Snider G. Chronic obstructive pulmonary disease: risk factors, pathophysiology and pathogenesis. Ann Rev Med 1989;40:411-29.

3 Pryor WA, Stone K. Oxidants in cigarette smoke: radicals, hydrogen peroxides, peroxynitrate, and peroxynitrite. Ann NY Acad Sci 1993;686:12-28.

4 Nakayama T, Church DF, Pryor WA. Quantitative analysis of the hydrogen peroxide formed in aqueous cigarette tar extracts. Free Radic Biol Med 1989;7:9-15.

5 Selby C, Drost E, Lannan S, et al. Neutrophil retention in the lungs of patients with chronic obstructive pulmonary the lungs of patients with chronic obstructive
disease. Am Rev Respir Dis 1991;143:1359-64.

6 Brown DM, Drost E, Donaldson K, et al. Deformability and CD11/CD18 expression of sequestered neutrophils in normal and inflamed lungs. Am ₹ Respir Cell Mol Biol 1995;13: mal and

7 Rahman I, Morrison D, Donaldson K, et al. Systemic oxidative stress in asthma, COPD, and smokers. Am $\mathcal{F}$ Respir Crit Care Med 1996;154:1055-60.

8 Rahman I, Skwarska E, MacNee W. Attenuation of oxidant/ antioxidant imbalance during treatment of exacerbations of chronic obstructive pulmonary disease. Thorax 1997;52: 565-8.

9 Dekhuijzen RPN, Aben KKH, Dekker I, et al. Increased exhalation of hydrogen peroxide in patients with stable and unstable chronic obstructive pulmonary disease. $A m \mathcal{F}$ Respir Crit Care Med 1996;154:813-6.

10 Nowak D, Antczak A, Krol M, et al. Increased content of hydrogen peroxide in the expired breath of cigarette smokers. Eur Respir $\mathcal{7}$ 1996;9:652-7.
11 Montuschi P, Corradi M, Ciabattoni G, et al. Breath condensate analysis of 8-isoprostane: a new approach for assessment of oxidative stress in patients with chronic obstructive pulmonary disease. Am $\mathcal{F}$ Respir Crit Care Med 1999;159:A798.

12 Chan-Yeung MA, Buncio DY. Leucocyte counts, smoking and lung function. Am f Med 1984;76:31-7.

13 Britton JR, Pavord ID, Richards KA, et al. Dietary antioxidant vitamin intake and lung function in the general population. Am f Respir Crit Care Med 1995;151:1383-7.

14 Ness AR, Khaw KT, Bingham S, et al. Vitamin C status and respiratory function. Eur f Clin Nutr 1996;50:573-9.

15 Shunemann HJ, Muti P, Freudenheim JL, et al. Oxidative stress and lung function. Am F Epidemiol 1997;146:939-48.

16 Grievink L, Smith HA, Ocke MC, et al. Dietary intake of antioxidant (pro)-vitamins, respiratory symptoms and pulmonary function: the MORGEN study. Thorax 1998;53: $166-71$.

17 Rice-Evans C, Miller NJ. Measurement of antioxidant capacity in biological fluids. Methods Enzymol 1994;234: $279-84$

18 Ellman GL. Tissue sulfhydryl groups. Arch Biochem Biophys 1959; 82:70-7.

19 Miller NJ, Rice-Evans CA. Spectrophotometric determination of antioxidant activity. Redox Report 1996;2:161-71.

20 Rahman I, MacNee W. Role of oxidants/antioxidants in smoking-induced airways diseases. Free Radic Biol Med 1996;21:669-81

21 Mazzetti A, Lapenna D, Pierdomenico SD, et al. Vitamin E, $\mathrm{C}$ and lipid peroxidation in plasma and arterial tissue of smokers and non-smokers. Atherosclerosis 1995;112:91-9.

22 Anderson R. Assessment of the roles of vitamin C, vitamin $\mathrm{E}$, and $\beta$-carotene in the modulation of oxidant stress mediated by cigarette smoke-activated phagocytes. Am 7 Clin Nutr 1991;53:358-61S.

23 Van Antwerpen VL, Theron AJ, Richards GA, et al. Vitamin E, pulmonary functions, and phagocyte-mediated oxidative stress in smokers and nonsmokers. Free Radic Biol Med 1995;18:935-41.

24 Morrison D, Rahman I, Lannan S, et al. Epithelial permeability, inflammation and oxidant status in the airspaces of chronic smokers. Am $\mathcal{F}$ Respir Crit Care Med 1999:159:473-9.

25 Nowak D, Kasielski M, Antczak A, et al. Increased content of thiobarbituric acid-reactive substances and hydrogen peroxide in the expired breath condensate of patients with stable chronic obstructive pulmonary disease: no significant effect of cigarette smoking. Respir Med 1999;93:38996.

26 van Lieshout EM, Peters WH. Age and gender dependent levels of glutathione and glutathione S-transferases in human lymphocytes. Carcinogenesis 1998;19:1873-5.

27 Liu CS, Wei YH. Age-associated alteration of blood thiol-group-related antioxidants in smokers. Environ Res 1999;80:18-24.

28 Bridges AB, Scott NA, Parry GJ, et al. Age, sex, cigarette smoking and indices of free radical activity in healthy humans. Eur 7 Med 1993;2: 205-8.

29 Borron W, deBoisblanc BP. Steroid therapy for chronic obstructive pulmonary disease. Curr Opin Pulm Med 1998; $4: 61-5$

30 Levine PH, Hardin JC, Scoon KL, et al. Effect of corticosteroids on the production of superoxide and hydrogen peroxide and the appearance of chemiluminescence by phagocytosing polymorphonuclear leukocytes. Inflammation 1981;5:19-27.

31 Rautalahti M, Virtamo J, Haukka J, et al. The effect of $\alpha$-tocopherol and $\beta$-carotene supplementation on COPD symptoms. Am f Respir Crit Care Med 1997;156:1447-52.

32 Bodner C, Godden D, Brown K, et al. Antioxidant intake and adult-onset wheeze : a case-control study. Eur Respir $\mathcal{F}$ 1999;13:22-30.

33 Schwartz J, Weiss ST. Dietary factors and their relation to respiratory symptoms. The Second National Health and Nutrition Examination Survey. Am f Epidemiol 1990;132: $67-76$.

34 Miederma I, Feskens EJM, Heederik D, et al. Dietary determinants of longterm incidence of chronic nonspecific lung diseases. The Zutphen study. Am F Epidemiol 1993;138:3745

35 Morabia A, Menkes MJS, Comstock GW, et al. Serum retinol and airway obstruction. Am F Epidemiol 1990;132:77-

36 Habib MP, Tank LJ, Lane LC, et al. Effect of vitamin E on exhaled ethane in cigarette smokers. Chest 1999;115:68490

37 Dow L, Villar TA, Coggon D, et al. Does dietary intake of vitamins $\mathrm{C}$ and $\mathrm{E}$ influence lung function in older people. Am f Respir Crit Care Med 1996;154:1401-4.

38 Steinberg FM, Chait A. Antioxidant vitamin supplementation and lipid peroxidation in smokers. Am $\mathcal{F}$ Clin Nutr 1998;68:319-27. 